appeared on the ward and who has co-operated in the admission procedure. The section, for example, cannot be used for an out-patient attending a hospital's Accident and Emergency Department". This would also include patients admitted in an unconscious state following an over-dose and those attending outpatient clinics. However, the code provides no guidance to the management of patients considered to have a serious mental illness and adjudged to be at risk to themselves or others in such circumstances. I consider it would be beneficial to provide appropriate guidance in the use of common law, Section 136 and further procedures for professionals involved in such situations.

With regard to Nominated Deputies, Section 5(3), paragraph 8.14,C states, "Only Registered Medical Practitioners who are Consultant Psychiatrists should nominate deputies". This appears to preclude the use of Section 5(2) in the general hospital setting if the responsible medical officer is not immediately available and begs the question of how a patient admitted for physical illness, who has, for example, an acute psychotic episode and wishes to leave hospital is to be managed.

Many general hospitals do not have a psychiatric unit on site. By and large our colleagues there are unfamiliar with the workings of the Mental Health Act and how it relates to them. Although some are resistant, most wish to understand its principles and practice and use it appropriately. It is thus unfortunate that this Code of Practice contains many omissions and ambiguities and appears to neglect the issues which arise in this setting where it should be offering clear guidance. These need to be urgently addressed.

Hollymoor Hospital

Derek F. O'Sullivan Northfield, Birmingham B31 5EX

\section{Position Statement on Confidentiality}

\section{DEAR SIRS}

It has been reported that "the majority of people in Britain support the introduction of a legal right to prevent their medical records being disclosed to others" (Mathews, 1990). If this is true the College Statement (Psychiatric Bulletin, February 1990, 14, 97-109) will not be of comfort to this majority.

This Statement includes the recommendation that "patients should be made aware that appropriate sharing of information with other professionals is necessary in order to provide the best possible care, support and treatment". While it may be true that some sharing of information is desirable (necessary is surely too strong a term for much of adult general psychiatric practice) in certain circumstances, surely it is a separate and unacceptable further step to actively disseminate information or passively allow it to be taken without the patient's permission, except where there is a clear risk to safety or health. Perhaps the patient would opt for slightly less than the best possible care from a multidisciplinary team but with added confidentiality.

As the past secretary of the British Medical Association, Dr Havard, noted in a Green College Lecture (1989), "It would be difficult to name a democracy in the Western World that pays less respect to confidential medical information than the United Kingdom". The College's Statement while appearing to recognise the special nature of psychiatric notes (they are likely to contain more information and more sensitive information than general medical notes) does not follow with the then more obvious proposal that the notes should be treated in a more sensitive (confidential?) way, but rather the opposite as exemplified by the recommendation on shared information.

Birch Hill Hospital

D. M. BOWKER

Rochdale OL12 9QB

\section{References}

HAVARD, J. D. (1989) The responsibility of the doctor: Green College Lectures. British Medical Journal, 299, 503-508.

MATHEWS, V. (1990) Backing for secrecy law on medical files. Daily Telegraph, 1 January.

\section{Self-referrals to a psychiatric clinic}

\section{DEAR SIRS}

We would like to clarify a number of points made in the letter by Grant et al (Psychiatric Bulletin, February 1990, 14, 91-92) reporting on referrals to Ashmore House and commenting on our paper concerning the Mental Health Advice Centre (MHAC) in London (Boardman \& Bouras, 1989).

First, there appears to be a misunderstanding concerning the sex ratio of GP and self-referrals. In the Lewisham data there was an excess of females in both GP and self-referrals. However, in comparison to the GP referrals there was a significant and relative excess of males in the self-referrals (43\% v. $33.5 \%)$. This relative excess is also seen in Grant et al's data shown in their Table (39.2\% v. 30.5\%). Contrary to what Grant et al report in their letter, this difference is significant $\left(\chi^{2}=7.7559, P<0.01\right)$. Hutton (1985) reporting on the lower centre noted an absolute excess of males.

Second, Grant $e t$ al state that we suggested an excess of males in social classes I and II in our selfreferral group. We did not. There was a significant excess of classes I/II in the self-referral group compared to the GP referral group, but this applied to 